\section{Response to: 'Towards optimal cut-off trough levels of adalimumab and etanercept for a good therapeutic response in rheumatoid arthritis. Results of the INMUNOREMAR study' by Sanmarti et al}

We thank Sanmarti $e t a l^{1}$ for their interest in our study ${ }^{2}$ and the confirmation of our results in Caucasian patients with rheumatoid arthritis (RA). We agree that monitoring of serum drug trough levels would help to optimise anti-tumor necrosis factor (TNF)- $\alpha$ therapy for patients with RA in clinical practice.

The serum drug trough levels in our patients with RA who showed good therapeutic response were very close to those observed by Sanmarti et al, ${ }^{1}$ possibly reflecting a similar status in pharmacokinetics in different ethnic populations. However, the drug trough levels may vary with different detection methods, dosing and timing of the used drug or concomitant disease-modifying antirheumatic drugs ${ }^{2-4}$ and may be further complicated by the presence of antidrug antibodies. ${ }^{5}$

Although not yet addressed in the updated 2013 European League Against Rheumatism recommendation, ${ }^{6}$ the determination of drug trough levels would be a valuable guide for clinicians to optimise dosing of biologics according to a personalised treatment algorithm ${ }^{2} 3_{7}$ and avoid overtreatment for patients with RA receiving anti-TNF- $\alpha$ therapy. ${ }^{2}{ }^{8}$ For example, Pouw $e t a l^{3}$ have identified the therapeutic range of adalimumab trough levels at 5$8 \mu \mathrm{g} / \mathrm{mL}$ for maximal clinical response, providing a useful reference for downtitration of adalimumab dose. However, the optimal cut-off trough levels of adalimumab and etanercept which can predict a good therapeutic response in patients with RA should still be validated in longitudinal and larger scale studies.

\section{Der-Yuan Chen, ${ }^{1,2,3}$ Yi-Ming Chen ${ }^{1,2}$ \\ ${ }^{1}$ Division of Allergy, Immunology and Rheumatology, Taichung Veterans General Hospital and Faculty of Medicine, National Yang Ming University, Taipei, Taiwan ${ }^{2}$ Institute of Biomedical Science and Rong Hsing Research Center for Translational Medicine, National Chung Hsing University, Taichung, Taiwan \\ ${ }^{3}$ Institute of Microbiology and Immunology, School of Medicine, Chung Shan Medical University, Taichung, Taiwan}

Correspondence to Dr Der-Yuan Chen, Division of Allergy, Immunology and Rheumatology, Taichung Veterans General Hospital, No. 1650, Sec. 4, Taiwan Boulevard, Taichung 40705, Taiwan; dychen@vghtc.gov.tw
Contributors All authors made substantive intellectual contributions to the present response and approved the final manuscript. Y-MC drafted the manuscript and D-YC drafted and revised the manuscript.

Competing interests None.

Provenance and peer review Commissioned; internally peer reviewed.

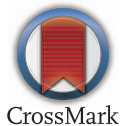

To cite Chen D-Y, Chen Y-M. Ann Rheum Dis 2015;74:e43.

Received 10 March 2015

Accepted 15 March 2015

Published Online First 4 April 2015

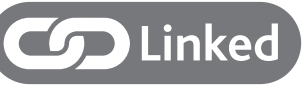

http://dx.doi.org/10.1136/annrheumdis-2015-207530

Ann Rheum Dis 2015;74:e43. doi:10.1136/annrheumdis-2015-207543

\section{REFERENCES}

1 Sanmarti R, Inciarte-Mundo J, Estrada-Alarcon P, et al. Towards optimal cut-off trough levels of adalimumab and etanercept for a good therapeutic response in rheumatoid arthritis. Results of the INMUNOREMAR study. Ann Rheum Dis 2015; 74:e42.

2 Chen DY, Chen YM, Tsai WC, et al. Significant associations of antidrug antibodies levels with serum drug trough levels and therapeutic response of adalimumab and etanercept treatment in rheumatoid arthritis. Ann Rheum Dis 2015;74:e16.

3 Pouw MF, Krieckaert CL, Nurmohamed MT, et al. Key findings towards optimising adalimumab treatment: the concentration-effect curve. Ann Rheum Dis 2015;74: 513-18.

4 Burmester GR, Kivitz AJ, Kupper $\mathrm{H}$, et al. Efficacy and safety of ascending methotrexate dose in combination with adalimumab: the randomised CONCERTO trial. Ann Rheum Dis 2014. Published Online First: 18 Feb 2015. doi:10.1136/ annrheumdis-2013-204769

5 Wolbink GJ, Aarden LA, Dijkmans BA. Dealing with immunogenicity of biologicals: assessment and clinical relevance. Curr Opin Rheumatol 2009;21:211-15.

6 Smolen JS, Landewé R, Breedveld FC, et al. EULAR recommendations for the management of rheumatoid arthritis with synthetic and biological disease-modifying anti-rheumatic drugs: 2013 update. Ann Rheum Dis 2014;73:492-509.

7 Krieckaert CL, Nair SC, Nurmohamed MT, et al. Personalised treatment using serum drug levels of adalimumab in patients with rheumatoid arthritis: an evaluation of costs and effects. Ann Rheum Dis 2015;74:361-8

8 Garcês S, Antunes M, Benito-Garcia E, et al. A preliminary algorithm introducing immunogenicity assessment in the management of patients with RA receiving tumor necrosis factor inhibitor therapies. Ann Rheum Dis 2014;73:1138-43. 